\title{
CRÓNICA DE UN ESTRENO: LO INVISIBLE (1928), DE "AZORÍN"
}

\author{
Pilar NIEVA DE LA PAZ \\ C.S.I.C. Madrid
}

Entre 1925 y 1936 Azorín escribió varias obras de teatro así como numerosos artículos sobre temas ligados al mundo de la escena (Pasquariello, 1959, pág. 186). Tanto en unas como en otros la renovación de la realidad dramática española fue motivo de atención y esfuerzo constante. En sus artículos de la época se recoge perfectamente esta inquietud ante lo que él consideraba un momento de transición desde la agotada fórmula naturalista hacia la incorporación urgente y necesaria de nuestro país a las corrientes teatrales de la vanguardia europea . Dentro de este contexto de renovación y búsqueda de nuevos cauces, la obra dramática azoriniana cobra especial relieve para un investigador actual.

Los historiadores del teatro español del primer tercio de siglo han discutido profusamente acerca del valor y trascendencia que la producción dramática de Azorín ha tenido en el teatro posterior. Creo por ello de interés intentar reconstruir cuál fue la valoración que la crítica periodística y especializada coetánea hizo de su obra y qué relación guarda este balance crítico con la recepción que el teatro azoriniano ha tenido en las décadas siguientes a su escritura y representación. El enorme alcance que una investigación semejante supondría excede los límites de un breve artículo. Mucho más sensato parece iniciar esta línea de análisis de la producción teatral azoriniana a partir del estudio de una obra concreta, que ha sido considerada tradicionalmente como

* Este trabajo forma parte del proyecto de investigación teatral "El teatro español contemporáneo: La escena madrileña 1900-1936", dirigido por M" Francisca Vilches de Frutos (CSIC, Madrid) y Dru Dougherty (University of California, Berkeley), y ha sido financiado por la C.I.C.Y.T. Agradezco los datos relativos al número de representaciones y crítica en provincias que nos han facilitado los directores del proyecto junto con M" Teresa García-Abad.

1. Vid. "La renovación del teatro", $A B C, 11$-VIII-1927 y "El porvenir del teatro", $A B C, 10-X I-1927$. Ambos aparecen recogidos en su libro Escena y Sala. También resulta interesante en este sentido "Una obra y un estreno" (23-III-1927), publicado en otra de sus colecciones de artículos teatrales — La Farúndula-, pp. 197-219. 
una de las más destacadas de la dramática azoriniana y que, por otra parte, fue estrenada en peculiares circunstancias.

A continuación se presenta una revisión y análisis de los comentarios que los críticos teatrales de finales de los años veinte publicaron inmediatamente después del estreno de Lo Invisible. Merece especial atención el tan debatido carácter surrealista de la citada obra que, paradójicamente, apenas fue reseñado en la prensa del momento. La recepción más positiva que la trilogía ha recibido por parte de la crítica académica posterior, en relación con la acogida que le dispensaron sus coetáneos, ha sido el objeto de un artículo que complementa el presente estudio (Nieva, 1990). En él comento brevemente algunos de los trabajos que se han publicado en las últimas décadas sobre el autor alicantino. Casi todos ellos coinciden en una revalorización de la obra, frente a las críticas no tan halagüeñas que se publicaron en la prensa con motivo de su estreno en 1928. Por otro lado, el debate sobre el surrealismo de la citada trilogía, que algunos desvían recogiendo el término azoriniano de "superrrealismo" hacia una comprensión personal y heterodoxa del movimiento vanguardista francés, ha sido también un tópico insoslayable en los estudios posteriores de los especialistas.

Lo Invisible es una trilogía de piezas teatrales en un acto que se estrenó en la recién creada Sala Rex, de Madrid, el 24 de Noviembre de 1928, estando la presentación a cargo de un grupo de aficionados que ponía así en marcha un proyecto de "teatro de arte". El grupo, dirigido por el conocido hombre de teatro y habitual colaborador de Margarita Xirgu, Cipriano Rivas Cherif, adoptó el nombre de "El Caracol", presentándose por primera vez ante el público con la escenificación del "Prólogo" que precede a la citada trilogía, dos de sus piezas en un acto (La arañita en el espejo y Doctor Death, de 3 a 5 ) y una obrita de Chejov - la comedieta cómica Un duelo- ${ }^{2}$. Esta última pieza vino a cubrir el tiempo que, presumiblemente, debería haber correspondido a la representación de la segunda de las partes de la trilogía, El segador ( Monleón, 1975, pág. 243).

2. Para más información acerca del citado grupo puede consultarse Gordón, pág. 16, Aguilera, pág. 234 --donde se alude a la primera representación de "El Caracol" ("Compañía Anónima Renovadora del Arte Cómico Organizado Libremente") y se anticipa parte del programa que llevaron a cabo posteriormente-, y la reciente edición de Margarita Ucelay del texto lorquiano Amor de Don Perlimplín con Betisci en su jardín. Esta última comenta en su introducción los esfuerzos renovadores al frente de teatros independientes de Cipriano Rivas Cherif y, en relación con "El Caracol" y la Sala Rex, señala: "Habían conseguido esta vez un local independiente, un amplio sótano bien situado cerca de la Puerta del Sol, en la calle Mayor 8, al que llamarían Sala Rex. Espartanamente acondicionado, contaba con un pequeño escenario - algo más que una tarima- encuadrado entre cortinas. Pero si el local era austero, las intenciones de El Caracol eran muy loables. Se proponía llevar a escena obras no apropiadas para el teatro comercial o de autores noveles no consagrados o traducciones de teatro extranjero, y su principal objetivo era intentar educar, ilustrar, es decir, crear un público que supiese apreciar el buen teatro con todas sus posibles innovaciones" (Ucelay, 1990, pág. 139). La Sala Rex fue cerrada por la policía el 6 de Febrero de 1929 y la obra de Federico García Lorca, Amor de don Perlimplín, incautada por inmoral y prohibido su estreno. 
Ésta fue la única representación de la trilogía durante la temporada 28-29 y en ella intervinieron como intérpretes Natividad Zaro, Magda Donato, Regina, Eusebio de Gorbea, Felipe Lluch, Rivas Cherif, Ernesto Burgos y el propio Azorín ${ }^{3}$. Es necesario recordar aquí que las tres piezas que componen la trilogía azoriniana habían sido estrenadas el año anterior fuera de Madrid, pese a lo cual los críticos de la época se ocuparon del estreno madrileño sin hacer alusión a la acogida que dichas obras disfrutaron en sus anteriores representaciones ${ }^{4}$. Como veremos más adelante, el hecho de que la obra de Azorín fuera la base de la primera función organizada por el grupo"El Caracol" fue un aspecto que influyó decisivamente en las reseñas del estreno que se publicaron en los principales periódicos madrileños de la época.

De entre las más de veinte publicaciones periódicas consultadas se han podido localizar nueve reseñas del estreno que nos ocupa, número relativamente escaso si pensamos en la atención prestada habitualmente a los estrenos comerciales de autores de una categoría similar a la de José Martínez Ruiz, pero bastante más significativo cuando consideramos que se trata en este caso de una obra estrenada en un circuito alternativo. La expectación aludida puede atribuirse tanto a la importancia dentro del panorama literario español de su autor como a la lógica curiosidad ante un nuevo y prometedor proyecto encabezado por un directo de la talla de Rivas Cherif. Inman Fox, por su parte, ha explicado este hecho en razón de lo que considera un fenómeno extensible a casi todas las iniciativas teatrales azorinianas. Según este último crítico, la recepción de sus obras fue muy buena entre el público, de acuerdo con lo que se deduce de las incompletas reseñas facilitadas por Werner Mulertt:

Con las posibles excepciones de Brandy, mucho brandy y La guerrilla, las obras y traducciones de Azorín tuvieron un franco éxito de público, teniendo en cuenta, claro está, los límites impuestos sobre el teatro experimental [...]. Aunque habría que estudiar con más seriedad los periódicos y revistas del día, con leer el apéndice bien documentado del libro de Mulertt [...] podemos generalizar con bastante seguridad sobre cómo se recibían las obras de Azorín.

3. Estévez-Ortega, en su artículo de Nuevo Mundo, cita también como miembros de la agrupación a Juan Calibau, Carmen de Juan, Josefina Hernández y deja abierta la lista, que no recuerda completa. La nómina de intérpretes extraída de la información periodística no coincide totalmente, sin embargo, con la facilitada por Juan Aguilera Sastre: "Rivas Cherif contó en esta ocasión con la colaboración de Magda Donato, Salvador Bartolozzi, Felipe Lluch, Eusebio de Gorbea, Natividad Zaro, Gloria Martínez Sierra, Luis Lluch, Ramón Algorta y Enrique Suárez de Deza" (pág. 234).

4. La arañita en el espejo se estrenó en el teatro Eldorado, de Barcelona, por la "Compañía Rosario Iglesias", el 15 de Octubre de 1927; El segador se vio por primera vez en el teatro Pereda, de Santander, representada por la "Compañía de Rosario Pino", el 30 de Abril de 1927; finalmente Doctor Death, de 3 a 5 fue estrenada por esta misma compañía y en el mismo teatro dos días antes, el 28 de Abril de 1927. A propósito del estreno en Barcelona de La arañita, el periódico $L a V O z$ recogió la siguiente información publicada inicialmente en La Vanguardia de Barcelona: "Esta obrita de Azorín es para ser representada en un teatrito de reducidas dimensiones y ante un público escogido. Se trata de una producción al modo maeterleckiano. Una joven enferma presiente en varios pormenores que la muerte está al acecho. Su fina sensibilidad se altera y un ambiente de profunda tristeza es así generado. Y el autor consigue suscitar de manera penetrante, como agudas saetas que trajeran inquietud, un hondo malestar" (La Voz, 19-X-1927, pág. 2). En relación con el estreno en Santander de El Segador y Doctor Death, véase Heraldo de Madrid, 6-V-1927, pág. 5, donde se recogen interesantes datos sobre su puesta en escena. 
Ahí están los tópicos esperados como "no hay desenlace", "la obra es ilógica", etc., pero los críticos más prestigiosos - Enrique de Mesa, Enrique DíezCanedo, Gómez de Baquero- veían lo nuevo y lo elogiaban.

(Inman Fox, 1968, pág. 380)

Efectivamente, el libro de Werner Mulertt debe ser citado como el antecedente inmediato del presente trabajo. En él se incluyen interesantes extractos de las reseñas publicadas tras los estrenos de las obras de Azorín, con la significativa excepción de Lo invisible y Angelita, obras que apenas se resumen argumen-talmente y se abandonan con un ligero comentario (Mulertt, 1930, pp. 241-293).

La tónica general que ofrecen los comentarios críticos localizados es, por un lado, la expectación esperanzada ante el nacimiento del nuevo grupo artístico, que se presentaba sobre las tablas remitiéndose al magisterio del "Teatro de Arte" de Moscú y, por otro, una fría y, por lo general, poco favorable acogida de la obra del autor alicantino. No dejaron de señalarse, sin embargo, los logros que Azorín había alcanzado con su trilogía, aunque éstos no sirvieran para compensar los fallos que varios de estos críticos achacaron a la obra.

En lo que respecta al primer punto, el elogio y ánimo que se ofrece, aunque tal vez retóricamente, al grupo "El Caracol" fue prácticamente unánime. Su empeño declarado de trabajar por la renovación del arte teatral era favorablemente recibido, aunque algunos señalaran las dificultades que con toda seguridad tendría que vencer tan ambicioso proyecto:

He aquí de nuevo a Cipriano Rivas Cherif, animoso, diligente, alegre, entusiasta, acometiendo por enésima vez la tarea de dar a Madrid un escenario que sirva de laboratorio a curiosas experiencias teatrales. ¿Teatro nuevo?... Tal vez sea pedir demasiado o esperar lo improbable. Dios dirá... Con que sea teatro distinto podríamos contentarnos de momento. Teatro distinto, pues, en el sentido en que lo venimos solicitando unos cuantos amigos de la literatura dramática y del arte escénico.

\section{(Fernández Almagro, 1928)}

En general, la crítica coincidió en señalar la importante promesa que el grupo podía suponer para la escena madrileña, carente hasta el momento de "esos laboratorios estéticos, que confieren cierta dignidad espiritual a una sociedad y a una época". Las dos citas anteriores, de M. Fernández Almagro, ejemplifican bien esta benévola acogida, un tanto teñida de escepticismo por lo que respecta a la continuidad futura del grupo. Arturo Mori, Juan G. Olmedilla, el crítico de La Época y, en mayor o menor medida, todos los demás, alaban de similar modo este noble empeño innovador, siendo los más cautelosos en cuanto a sus posibilidades de realizar semejante empeño M. Albar y Luis Calvo.

Fue E. Estévez-Ortega, en Nuevo Mundo, el que mayor espacio dedicó a informar sobre el grupo recién creado, las características de la nueva sala y el repertorio de obras programado por "El Caracol". De este programa, en el que se incluyen el Orfeo, de Jean Cocteau; El terno del difunto, de R. M" del Valle- 
Inclán; Los libreros de viejo, de Pío Baroja; Si creerás tú que es por mi gusto y A las puertas del cielo, de Jacinto Benavente; La criolla, de Joaquín de Zugazagoitia; La curiosa imaginación, de César Falcón; Ifigenia, de Alfonso Reyes; El rapto de las Sabinas, de Leonid N. Andreev, y otras de Bernard Shaw, de Molière, de Carlo Goldoni, etc., Estévez afirma que supera con mucho el interés de la sesión inaugural. En cuanto a la Sala Rex, comenta:

Ya he dicho que es reducida, elegante, limpia... Se entra por un portal amplio, de aspecto lujoso y nuevo. Se pasa a un zaguán alfombrado y se entra en seguida en la sala. El techo es una cristalera; las paredes, de color crema, desnudas, con algún leve adorno, y está alumbrado por dos grandes arañas, en cuyos cristales se quiebra la luz en vivos reflejos brillantes. En uno de los ángulos está el escenario. Como el teatro de Meyer-Hold [sic], por ejemplo, también carece de embocadura, de telón, de decoraciones. Sobre la tarima, breve y reducida, actúan los actores. Las paredes están cubiertas por cortinajes de color opaco, a lo Gordón Craig, y realizan los practicables a la manera del teatro du Murais, de Bruselas, por ejemplo. No hay concha.

Y en semicírculo, las sillas donde se sienta el público. No hay palcos, ni preferencias, ni generales.

(Estévez-Ortega, 1928)

Después de informar acerca de la presentación del grupo, los críticos ofrecieron también un resumen de la conferencia sobre el teatro moderno que Azorín pronunció para inaugurar la sesión ${ }^{5}$. La charla azoriniana fue criticada por su vaguedad y escasa profundidad analítica, ya que, según estos críticos, no se ofrecían las causas de la evolución histórica que el autor alicantino exponía como origen del teatro actual.

E. Díez-Canedo comentó en su crítica la idea azoriniana de evolución de nuestro teatro desde los tiempos medievales hasta el momento actual, en el que Azorín había percibido un retorno a las antiguas aspiraciones idealistas, nacidas del horror a una guerra que llevó a la muerte a millones de seres humanos. A juicio del crítico de El Sol, este aspecto casi "místico" constituía tan sólo uno de los varios rasgos del teatro nuevo, y añadía que los que interpretaban el idealismo como un síntoma de resurgimiento religioso eran en ocasiones propagandistas de una doctrina determinada. "La guerra", escribe Canedo, "enseñó no tanto a mirar a otra vida como a desdeñar ésta; no tanto a negarle valor como a exaltar sus goces, más intensos cuanto más transitorios". Excepto Juan G. Olmedilla, crítico del Heraldo, que la calificó de "interesante" y Arturo Mori, de El Liberal ("Sobria, sintética, expresiva peroración"), los comentarios sobre la charla fueron, en general, poco favorables.

Por lo que se refiere a la trilogía de Azorín propiamente dicha, la pieza más elogiada fue, sin duda, Doctor Death, de 3 a 5 , tanto por su contenido dramático como por su sobrio estilo, logrado especialmente en el discurrir del

5. La conferencia, titulada "El teatro moderno" fue comentada con suficiente extensión en la mayor parte de estas críticas, destacando la sinopsis ofrecida por el crítico de La Época. 
diálogo. Así Luis Calvo observaba que, frente al fracaso de Azorín en su incursioón lírica hacia el misterio en las dos primeras piezas representadas, en Doctor Death "la expresión dramática alcanzó momentos muy felices". Juan G. Olmedilla señalaba, por su parte, que la pieza era "lo mejor del indeciso teatro azoriniano, porque sus intensas escenas se estremecen bajo el soplo auténtico del misterio, entre la interrogante de la vida y de la muerte, impenetrables". Arturo Mori se mostraba más moderado al afirmar que Doctor Death "tiene cierta hechura dramática que produce estremecimiento, y sobre todo, que está construido con arte y sentido moderno de la escena".

Mayores reparos, sin embargo, se observan en la crítica de La Época. Haciéndose eco de los comentarios del crítico Jorge de la Cueva, el anónimo comentarista de La Época ${ }^{6}$ calificó la trilogía de "un tanto macabra y no recomendable a los que teman a la muerte", añadiendo:

"Azorín" en la tercera parte de la trilogía acierta a producir emoción, pero lo estropea, porque no comprende que la psicología del público es tal que prefiere adivinar las cosas a que se las repitan. Esa es la diferencia entre el autor dramático y el escritor.

Varios de esos comentaristas coincidieron en su elogio del estilo azoriniano. Los diálogos fueron uno de los aspectos de la obra más debatidos por lo mismo que suponen un tema central de la concepción dramática de Azorín 7 . Para este autor, la primacia del diálogo constituía el pilar de la renovación teatral por él defendida, afirmando constantemente en sus trabajos teóricos que todo había de estar contenido en el diálogo, mientras que la escenografía debía ser considerada como un elemento teatral secundario.

M. Fernández Almagro declaraba al respecto que "la fineza de toque, la sobria y limpia expresión literaria" era prácticamente lo único positivo ofrecido por la obra de Azorín. El desacuerdo crítico, sin embargo, volvía a manifestarse también sobre este asunto. Si a juicio de Luis Calvo (por lo demás muy duro en su crítica de la obra), el diálogo de estas piezas pudo calificarse de "delicioso", comentaristas como E. Estévez-Ortega, que los tildó de "parlamentos prolijos, lentos, carentes de interés", y Jorge de la Cueva, que llegó hasta el extremo de denunciar "la torpeza de Azorín para el diálogo", coindieron en su considera-

6. En la misma línea se manifiesta Jorge de la Cueva, de La Época, cuando afirma: "El Doctor Death tiene más emoción, pero diluida y apagada, enfriada por el constante autoanálisis de la heroína; eso no hay que decirlo, hay que mostrarlo; no hay que explicar, sino dar la sensación; otra cosa es desconocer lo esencial en el teatro, que es la visión sintética" (pág. 6). Estévez-Ortega fue mucho más contundente al señalar que, sin el concurso de Rosario Pino (la actriz que estrenó la obra en Santander), el tipo de la enfermera resultaba insoportable e inducía a una constante comparación con La intrusa de Maeterlinck, comparación de la que la pieza de Azorín no podía más que salir malparada.

7. Para conocer el ideal dramático azoriniano, conviene consultar su artículo "Brandy, mucho brandy", 1945, pp. 191-196. Con respecto al diálogo afirma Azorín: "Y en la obra así el diálogo habría de ser una cosa esencial. ¡Ah, el arte del diálogo! Nadie sabe, hasta que ha hecho la prueba, lo difícil, lo terrible, lo arduo que es condensar en pocas palabras [... ] el pensamiento, las ideas, la vida, la sensibilidad toda de unos cuantos personajes" (pág. 195). También se refiere a este mismo asunto en varios de los artículos recogidos en Ante las candilejas, "Sobre el teatro", (pp. 84-88) y "Las acotaciones teatrales", (pp. 98-101). Más precisiones pueden encontrarse en Manso, pp. 208-222 y Riopérez, pp. 542-548. 
ción de los mismos como poco teatrales, repetitivos y faltos de interés dramático ${ }^{8}$.

Tanto el Prólogo como La arañita en el espejo recibieron, por su parte, frecuentes ataques. El crítico de El Debate fue el más duro en sus comentarios:

En el prólogo la verdad-muerte dice de sí lo bastante para que pronto se sepa quiénes son sus torpes interlocutores, que deben tener más interés en saberlo, que el público, que ya lo adivinó; no acaban de hacerle un interrogatorio concreto que prorrogue una respuesta categórica.

\section{(Cueva, 1928)}

El tema de la muerte acechante y tétricamente misteriosa fue considerado "macabro" (La Época) y sintomático de una sensibilidad anticuada que DíezCanedo calificó en El Sol como propia de fin de siglo. El mismo Azorín había traducido, según nos recuerda el citado crítico, La intrusa, de Maeterlinck, en 1896.

Entramos aquí en una cuestión que fue inevitable piedra de toque en estos trabajos críticos: la polémica acerca de la novedad que la obra representaba en el panorama teatral español de fines de los años veinte. Díez-Canedo dedicó casi toda su crítica a analizar el concepto de "teatro nuevo" en Azorín, así como a intentar vislumbrar su dudosa concreción en Lo invisible. Su postura al respecto no pudo ser más explícita:

¿Teatro nuevo? No. Conténtese con ser teatro serio, fino, interesante. La novedad en asuntos como el de Azorín también cabe: algún drama breve de Per Lagergvint [sic], escritor sueco, le añade la sal de las nuevas canteras.

(Díez-Canedo, 1928)

Resulta significativo que, nada más estrenarse, los críticos apuntasen ya a Maeterlinck como referente temático e incluso estilístico de la trilogía de Azorín. Este hecho resultó muy perjudicial en cuanto a la valoración de cualquier posible novedad en la obra:

Ni la trilogía Lo invisible (La arañita en el espejo, El segador y Doctor Death, de 3 a 5) - de inesquivables reminiscencias maeterlinckianas- ni la comedieta de Andrés Chejov Un duelo apuntan a novedad alguna, a la hora de ahora.

(Olmedilla, 1928)

8. La réplica que ofrece el propio Azorín a esta crítica que tan frecuentemente leyó y escuchó de sus contemporáneos puede encontrarse en su artículo "Los aficionados" (Dic. 1930), recogido en 1947, pp. 131-138, donde explica el carácter "oral" de sus diálogos, plagados de frases rápidas, incoherentes a veces debido a frecuentes interrupciones y sugestiones apenas apuntadas, diálogos que resultan así más auténticos y llenos de vida. Afirma también que las repeticiones en el diálogo no son algo arbitrario, sino por el contrario, totalmente necesarios para plasmar variantes psicológicas y sucesivos matices que van conformando paulatinamente la obra. 
E. Estévez-Ortega se mostró también escéptico acerca de la consideración de Lo invisible como obra adecuada para iniciar la andadura de un teatro de arte que pretendía ser sustancialmente renovador. Por su parte, el crítico de $L a V o z$, M. Fernández Almagro, presentó al autor de la obra como "campeón del teatro nuevo o distinto", si bien añadiendo: "Aunque el éxito no le haya acompañado en todas sus salidas, aunque sea discutible [...] la lógica de sus principios estéticos".

En las menciones habituales al público que asistió al estreno, se comentó repetidamente el ambiente propicio que reinaba en la sala, repleta como estuvo de intelectuales y aficionados a la vanguardia artística. Según el crítico del Heraldo, lo mejor del mundillo literario madrileño poblaba el recinto, destacando la significativa presencia de Ramón Gómez de la Serna. La asistencia de numerosos intelectuales fue señalada por algunos de estos críticos como el mejor medio de explicar un éxito de público con el que no parecían estar muy de acuerdo. Luis Calvo aludía así a "un público híbrido: algunos snobs, algunos curiosos de eso que llaman vanguardia algunos humoristas y murmuradores [...]. Un público blando, como el del Lyceum femenino" $(A B C)$.

Otro dato curioso que los críticos no dejaron de comentar fue la actuación del propio Azorín en el prólogo de la trilogía, interpretando el papel del "Autor". Hubo dos tipos de comentario a su intervención en el prólogo de la obra: por un lado, varios críticos no quisieron pronunciarse sobre las cualidades interpretativas del alicantino debido a la brevedad de su aparición sobre las tablas; por otro, hubo quienes juzgaron negativamente sus posibilidades como actor e incluso aprovecharon para llevar a cabo un ataque más personal y directo contra Azorín. Tan sólo Díez-Canedo mantuvo una opinión aparentemente favorable sobre este curioso debut interpretativo:

"Azorín", en su prólogo a Lo invisible, fue unos momentos actor. La Prensa ilustrada ha perpetuado sus actitudes. Al público le dio la impresión que pretendía: la de un autor entre sus comediantes, un poco sorprendido por la insospechada importancia que adquiría uno de ellos.

(Díez-Canedo, 1928)

Por lo que respecta a la realización escenográfica del espectáculo, los datos que se pueden extraer de estos comentarios periodísticos son realmente escasos. Arturo Mori apuntaba brevemente: "Un estrado simplista en la Sala Rex. Cortinajes combinados por Bartolozzi. Focos a lo Pitoeff, añadiendo al final de su crónica que el estrado estaba excesivamente bajo (El Liberal). Se incluyeron además dos fotografías de la representación en la revista Nuevo Mundo (una escena de Doctor Death y otra de Un duelo, de Chejov) y un dibujo, en $A B C$, de la misma pieza azoriniana.

Finalmente debo señalar que el balance global ofrecido por estas críticas es doble: cauto, pero favorablemente predispuesto en cuanto se refiere a la presentación de "El Caracol" y moderadamente negativo en relación con el estreno de Lo invisible. En general, se puede afirmar que los reseñadores del 
estreno valoraron más positivamente el futuro próximo de "El Caracol" como grupo abierto a la experimentación de nuevas fórmulas teatrales que la aportación que la trilogía de Azorín podía suponer en este sentido. La práctica totalidad de la crítica consideró un error por parte de Rivas Cherif el haber elegido para el debut de su grupo experimental la obra de un autor consagrado y cuya dimensión vanguardista era frecuentemente discutida. Desconocemos las razones que llevaron al citado director a iniciar la andadura de su grupo con la trilogía azoriniana, pero la recepción del estreno prueba que los comentaristas del momento consideraban poco "novedoso" al autor alicantino.

Las críticas más adversas fueron las de E. Estévez-Ortega, Jorge de la Cueva y la del crítico de La Época, el cual toma gran parte de sus argumentos del anterior al mismo tiempo que cita también con profusión a E. Díez-Canedo. Los demás intentaron compensar sus frecuentes ataques a la obra con los ánimos que brindaban, al menos teóricamente, a cualquier honesto esfuerzo de renovación. Algunos no quisieron exponer claramente su postura ante la obra, conducta que Díez-Canedo llevó hasta el extremo al centrarse en el comentario de la charla azoriniana y dejar casi de lado el análisis de la trilogía propiamente dicha.

No se puede ignorar, sin embargo, que esta general tendencia a una crítica poco favorable de la trilogía reseñada pudo haber estado influida por las difíciles relaciones que Azorín mantuvo con los críticos por estos años. Sus frecuentes artículos atacando el estado del ejercicio crítico teatral en nuestro país le involucraron en duras polémicas con los periodistas de la época que, generalmente, no le perdonaron sus ataques e incluso la ridiculización que de ellos hiciera en la obra escrita en colaboración con P. Muñoz Seca, El clamor.

Es necesario destacar, asimismo, que la posible adscripción surrealista de la obra fue totalmente ignorada en estos trabajos críticos, a pesar de las reiteradas declaraciones de su autor en este período en relación con el surrealismo. Como única excepción podemos mencionar la insinuación prudente de $\mathrm{M}$. Albar en su breve crónica de El Socialista:

El programa de anoche era sugestivo: charla de Azorín sobre el teatro moderno y su trilogía de Lo invisible, cuadros breves, en los que hay un amplio margen para lo subconsciente. ¿Superrealismo, Azorín?

\section{(Albar, 1928)}

Este hecho contrasta con la atención que la crítica posterior ha concedido a la dilucidación del problema. Del mismo modo es contrario a la presentación que Mulertt, un especialista coetáneo de José Martínez Ruiz, hacía de esta obra en el apéndice ya citado de su obra, comentándola simultáneamente con las conferencias que sobre el surrealismo estaba dando su autor por las fechas de este estreno. Paradójicamente, su anterior estreno, Brandy, mucho brandy (1927), había provocado una violenta polémica en torno al tema, polémica que algunos críticos del momento consideraron como la aportación más importante 
de la obra al panorama escénico del momento, ya que obligaba al mundo teatral e intelectual de entonces a manifestarse sobre la cuestión y contribuía así a difundir las nuevas teorías vanguardistas.

Jesús García Gallego en su libro sobre la recepción del surrealismo en España considera el "caso Azorín" como un fenómeno especial, puesto que este autor, dice, "fue el único capaz de desencadenar una gran polémica, no sólo a nivel de crítica especializada, sino también en la prensa diaria"". Pese a este hecho, los comentaristas del año 1928 parecieron ignorar los antecedentes polémicos del estreno que nos ocupa y dejaron a un lado la "cuestión surrealista" en sus reseñas.

\section{BIBLIOGRAFÍA CITADA}

ALBAR, M. 1928. "Crónica Teatral. El grupo Caracol", El Socialista, 25-XI, pág. 3.

AGUILERA SASTRE, J. 1984. "La labor renovadora de Cipriano Rivas Cherif en el teatro español: El mirlo blanco y El cántaro roto (1926-1927)", Segismundo, 39-40, pp. 233-245.

AZORÍN. 1945. La Farándula, Zaragoza, Librería General, 1945.

- 1947 a. "Ante las candilejas", Obras completas, vol. IX, Madrid Aguilar.

- 1947 b. Escena y Sala, Zaragoza, Librería General.

CALVO, L. 1928. "Presentación del grupo teatral del Caracol", ABC, 25-XI, pp. 45-46.

CUEVA, J. de la. 1928. "Sala Rex: Presentación del grupo teatral Caracol", El Dehate, 25-XI, pág. 6.

DÍEZ-CANEDO, E. 1928. “Azorín, actor y autor dramático", El Sol, 25-XI, pág. 4.

DOMENECH, R. 1968. “Azorín dramaturgo", Cuadernos Hispanoamericanos, 226-227, pp. $390-405$.

ESTÉVEZ-ORTEGA, E. 1928. "Debut de Azorín como actor", Nuevo Mundo, 7-XII, pp. $1-2$.

FERNÁNDEZ ALMAGRO, M. 1928. "Función del Caracol en la Sala Rex”, La Voz, 26-XI, pág. 2.

GARCÍA GALLEGO, J. 1984. La recepción del Surrealismo en España (1924-1931), Granada, Antonio Ubago.

GORDON, J. 1965. Teatro experimental español, Madrid, Escelicer.

INMAN FOX, E. 1968. "La campaña teatral de Azorín", Cuadernos Hispanoamericanos, 226-227, pp. 375-389.

9. Sobre este punto, véase García Gallego 1984, pp. 60-64. Se recogen aquí tres interesantes artículos del período que nos ocupa a propósito del surrealismo azoriniano: Aristo, "¿Qué es el superrealismo?", Gaceta Literaria (Mayo, 1927); A. Espina, "Azorín. Superrealismo, prenovela", Revista de Occidente 83 (1930), y R. Silva Castro, "Azorín y el Superrealismo", Bolívar (Mayo, 1930). 
MANSO, Ch. 1987. "Recepción del surrealismo en Azorín hasta Brandy, mucho brandy", Litoral, pp. 208-222.

MONLEÓN, J. 1975. El teatro del 98 frente a la sociedad española, Madrid, Cátedra.

MORI, A. 1928. "Las novedades de ayer. Del Caracol, al Infanta Beatriz", El Liberal, 25 XI, pág. 5.

MULERTT, W.1930. Azorín (José Martínez Ruiz), Madrid, Biblioteca Nueva, pp. 241-293.

NIEVA, P. 1990. "Recepción crítica de Lo invisible, de José Martínez Ruiz (Azorín)", Surrealismo español (Actas del Seminario Internacional), Madrid, UAM. En prensa.

OLMEDILLA, J.G. 1928. "Presentación del grupo Caracol en estrenos de Azorín y Chejov", Heraldo de Madrid, 26-XI, pág. 5.

PASQUARIELLO, A.M. 1959. "The Dramatic Formula of Azorín", Symposium, XIII, pp. 186-194.

RIOPÉREZ Y MILÁ, S. 1979. "El teatro de Azorín", Azorín íntegro, Madrid, Biblioteca Nueva, pp. 542-548.

UCELAY, M. (ed.). 1990. Amor de Don Perlimplín con Belisa en su jardin, de F. García Lorca, Madrid, Cátedra. 